\title{
Conflicting Values in the GM Food Crop Debate
}

Jennings $\mathbf{R C}^{*}$

Department of History and Philosophy of Science, University of Cambridge, Cambridge, UK

*Corresponding author: Jennings RC, Department of History and Philosophy of Science, University of Cambridge, Cambridge, UK, Tel: 0441223214658; E-mail: rcj11@cam.ac.uk

Received date: August 06, 2015; Accepted date: September 10, 2015; Published date: September 15, 2015

Copyright: $\odot 2015$ Jennings RC. This is an open-access article distributed under the terms of the Creative Commons Attribution License, which permits unrestricted use, distribution, and reproduction in any medium, provided the original author and source are credited.

\begin{abstract}
The GM debate ranges over a wide spectrum of issues, which can be grouped under three main headings. First, and of most immediate concern, is the debate over the possible effect of GM foods on human health. Second is the debate over the impact of GM crops on the environment. And last is the socio-economic impact of GM agriculture. This paper addresses the first issue, the safety of GM foods, and why this debate has not been resolved in the 15 or more years it has been running. This paper will provide a careful analysis of an early debate over the safety of GM food that marks the turning point in the nature of the GM debate. The paper argues that at this point the debate ceased to be an open and reasoned debate over science and became an ongoing, and often emotional, attempt to silence the critics of GM technology.
\end{abstract}

Keywords: GM food crops; Safety; Hazards; Human health; Science and values; Product vs. process; Arpad pusztai

\section{Introduction}

The debate over GM food crops has been going on since the 1990s. The debate ranges over a wide spectrum of issues, which can be grouped under three main headings. First, and of most immediate concern, is the debate over the possible effect of GM foods on human health. Second is the debate over the impact of GM crops on the environment. And last is the socio-economic impact of GM agriculture. This paper addresses the first debate, the possible health hazards of GM foods, and why it has not yet been resolved. The impact of GM crops on the environment is now well known - the rise and spread of "superweeds", weeds resistant to herbicides, is well documented [1-3] and the engineering of resistance to even stronger herbicides is well underway with the US EPA approval of plant varieties that are tolerant of the herbicides 2,4-D [4] and approval imminent for the use of dicamba in Monsanto's Roundup Ready XTend crop system [5]. The socio-economic debate is mainly concerned with the role of the agro-chemical industry in developing nations. This is still an open debate. On the one hand, critics of GM crops worry that the agrochemical industry will exploit the land and labour resources of developing nations, while advocates of GM crops believe that the technology can make a positive contribution to food production in these countries.

It is important to note that many advocates of GM crops are motivated by the possible benefits that GM technology may bring to humanity, and especially to the hungry people in the developing world. Other advocates, in the commercial world, are motivated by the profits that GM technology may bring to farmers and, of course, to their own industry. This paper will provide a careful analysis of a debate over the safety of GM crops and food that took place in 1999, a debate that marks the turning point in popular attitude towards GM technology. The values underlying these two different sources of GM advocacy will be identified in that analysis. Their role in the shift from an open and reasoned debate over the science of GM to an ongoing, and often emotional, attempt to silence the critics of GM technology will be discussed. This will show how and why many advocates of GM are entirely opposed to any research that indicates possible hazards of GM crops and food.

\section{The Logic of the Debate}

\section{Process versus product and the problem of induction}

One of the issues in the debate over GM crops is whether GM crops are all harmful to health or not. Advocates of GM argue that the critics cannot claim that all GM products are hazardous to health. That is, they cannot condemn the process of GM. Even though there is evidence that some GM foods are hazardous, that doesn't mean that all are. We cannot make the general claim on the basis of some particular claims - what philosophers call the problem of induction. For this reason GM advocates argue that it is the product that must be evaluated, and not the process which produces the product. However the advocates often go further than this. They use the same inductive reasoning in defence of GM foods. They claim that there is no evidence of harm resulting from consumption of GM foods. Apart from GM activists, GM advocates do not categorically claim that GM food is harmless, but the implication that we are meant to draw from what they do say is that it is generally harmless. We are invited to fall into the inductivist trap and conclude that the process of producing GM foods is non-hazardous, because there is no evidence of harm resulting from consumption of GM foods.

Of course the problem of induction is a problem for all of science. The impossibility of establishing a general claim on the basis of a few (or even many) instances was established by Karl Popper early in the $20^{\text {th }}$ Century. It is now generally accepted by philosophers of science. Popper considered all such general claims as no more than hypotheses, to be rejected when a counter instance was found. The upshot of this problem is that general conclusions in science are never secure. It is an occupational hazard of science that whatever general claim is made may be shown to be wrong. Unlike Popper, however, we do tentatively 
Page 2 of 8

accept generalizations as true if enough of their instances turn out to be true and none turn out to be false.

Even though we can never prove a hypothesis, we can gather evidence in support of the hypothesis and, with sufficient support, we can tentatively accept the hypothesis (even though it has not been proved). The evidence consists of true instances of the hypothesis. When the hypothesis is that the GM process does not produce hazardous products, the evidence would consist of the non-hazardous products of GM technology. If we do find a product that is harmful to health, this would immediately falsify the hypothesis that the process of producing GM foods is non-hazardous. Similarly, to find a product of GM technology that is not hazardous to health falsifies the hypothesis that all products of GM technology are hazardous to health. The tentative nature of the hypothesis that GM technology is not hazardous to health, means that the agro-chemical industry that depends on this hypothesis is in a precarious position. Any case of a hazardous GM crop falsifies the hypothesis. The fact that some GM crops have been shown hazardous to health means that we cannot categorically claim that no GM crops are hazardous to health.

Advocates of GM crops insist that there is a consensus, or tentative acceptance, in the scientific community of the hypothesis that GM crops are safe. But, logically, this hypothesis cannot be proved. There are those in the scientific community who argue that at least some products of GM are not safe, and that therefore the hypothesis cannot be justified. Indeed, if this is so, if some crops are harmful, then the hypothesis that all are safe has been proved to be false. The only way that GM advocates can defend their general claim is by showing that these apparently unsafe products are actually safe. But this is a more difficult task. Evidence of the harm that particular products may cause is typically the result of controlled experiments-in this case, experiments wherein rats are fed diets which differ only in the presence or absence of GM crop in question.

\section{Controlled experiments}

The use of controlled experiments is widespread and well established. Initially proposed by Francis Bacon in the $17^{\text {th }}$ Century, and reinforced by subsequent philosophers, including John Stuart Mill, the method has a venerable history, and over time it has been improved through the use of statistical analysis. But the basic idea is simple and compelling. If two sets of rats are fed diets which differ in only one aspect, and if the rats in one of those sets show an adverse reaction, then it is pretty clear that the reaction is a result of that aspect in which their diets differed.

Using the method of controlled experiments, there is some hope that at least the particular instances on which our hypotheses are based can be established. In a word, it seems that we can use the empirical method to establish, for any particular instance, whether a GM crop is hazardous to health.

\section{Problems with controlled experiments}

Alas, even the controlled experiment cannot securely establish empirical conclusions. There may, for example, be some other aspect of the rats' diet that we did not notice, or take account of, which led to the adverse reaction. Or a critic may argue that it isn't really an adverse reaction, or that it isn't significant. The problem is that we can never be sure we have taken into account all relevant aspects of an experiment. This means that we can never be sure we have securely established a result - critics can always raise further objections. So it appears that science is never conclusive - nothing is proved once and for all. Science is based in part on empirical work, and replication, and over time relevant facts and variables emerge, but they are not always found straight away. Another part of science is open and reasonable discussion within the community of science. Scientific knowledge emerges from this open and reasonable discussion as a consensus within the community, a consensus based on empirical results. Because science in not conclusive, because there are always further objections that can be made against any claim, including the results of empirical study, it is possible for other interests, or values, to play a role in drawing conclusions. If we do not like the conclusions our rivals draw, we can always raise further objections to their conclusions. Even when, from a scientific point of view their conclusions seem compelling, we can continue to raise scientific objections. This is the unfortunate situation of science. Science is not conclusive.

\section{Consensus}

However, it is possible to reach a consensus, through open and reasonable debate, and in most cases this fairly quickly resolves disagreements. But in the debate over the safety (or not) of GM products, the consensus has not been reached. It is claimed that there is a consensus that GM crops are non-hazardous. In 2012 the Board of Directors of the American Association for the Advancement of Science (AAAS) issued a statement in which they claimed categorically that: “... the science is quite clear: crop improvement by the modern molecular techniques of biotechnology is safe [6]." They mention various other professional bodies which have made similar claims. But too many in the scientific community do not agree with this general hypothesis. Their disagreement is based on empirical results of controlled experiments. As indicated above, even controlled experiments can be contested, and these are contested by those who defend the general claim, or similar claims, made by the Directors of the AAAS.

In response to the AAAS claim, and many others made around the same time, the European Network of Scientists for Social and Environmental Responsibility (ENSSER) circulated a statement to the effect that there is no scientific consensus on GMO safety [7]. The statement was published in October 2015, and has been signed by more than 300 scientists and legal experts involved in this work. This statement is extensively documented with the arguments and empirical findings which support the claim that there is no scientific consensus. The statement was followed up by a discussion in 2015 in which the arguments and evidence were brought up to date [8]. In support of the claim that there is no consensus, the discussion considers two (out of many) reviews of the scientific literature on the safety of GM food. It takes one review which illustrates the lack of consensus and one which supports the consensus. The former [9], a comprehensive review of feeding studies, found an even balance in the number of research groups reporting the safety of GM plants and those raising serious concerns. A further finding of this review was that:

...most of the studies demonstrating that GM foods are as nutritional and safe as those obtained by conventional breeding, have been performed by biotechnology companies or associates, which are also responsible of commercializing these GM plants.

The second review is one which is often cited by those defending the safety of GM foods [10]. An analysis of the studies reported in this review shows that there are differences between those animals which were fed GM foods and those which were not, but the review does not 
consider these differences as significant. However, there is no consensus on whether these differences are significant or not.

This discussion of the ENSSER statement goes on to mention a number of other studies indicating hazards in GM foods and notes that "these studies have not been followed up by targeted research that could confirm or refute the initial findings." In their words, the science is incomplete.

A more recent review of the safety of GM by Alessandro Nicolia et al. surveys more than 1,700 scientific papers, reviews, relevant opinions and reports which address the question of GM safety [11]. He states that:

The scientific research conducted so far has not detected any significant hazards directly connected with the use of GE crops; however, the debate is still intense.

Clearly, as of June 2013 when the review was accepted, there was still no consensus. Does Nicolia establish the safety of GM crops? First it should be pointed out that only just over 300 of these papers etc. are concerned with animal health(204) or unintended effects(104) [12]. But more importantly, it should be noted that he overlooked a number of important studies indicating significant hazards to health connected with the use of GE crops. Included in these are studies by Seralini [13] and Malatesta [14].

\section{Dissent}

A surprising aspect of the discussion over the hazards of GM crops, that is not generally found in other scientific discussions is the virulence with which those who identify hazards are attacked. In general, discussions over scientific claims are open, reasonable, and confined to the scientific issues. But the heat and tension that has characterized the discussion of whether GM foods are harmful is surprising. The reasons are slightly complicated, but if we look closely at how the heat and tension came into this discussion it is at least understandable.

\section{Origins of the GM Food Debate - 1999}

In the preface to their 1999 report [15] on genetically modified crops, the Nuffield Council on Bioethics states that:

When the Working Party began work in January 1998 there was little visible public anxiety about genetically modified (GM) crops and almost no press interest in the subject....It need hardly be said that while we have been working, the safety of GM crops and their environmental impact have become hotly debated issues....

Between the formation of the working party and the final report, the debate was sparked off by Arpad Pusztai in a two and a half minute interview on Granada Television's programme World in Action. In the interview, broadcast on the 10th of August 1998, Pusztai reported the results of his (nearly complete) research on GM potatoes.

The form of experiment he adopted in his research was the standard controlled experiment. According to the simplified version of the experiment discussed in the following, Pusztai's experiment had three groups of rats. The first group, the control group, was fed a diet consisting of a particular line of potatoes; the second group was fed that line of potatoes genetically modified to express the lectin Galanthus nivalis agglutinin (GNA, which increases pest resistance); the third group was fed the non-GM potatoes to which was added an amount of GNA equivalent to that expressed in the GM potatoes.
What Pusztai's experiments showed was that the second group, eating GM potatoes suffered significantly more ill effects than either of the other two groups. This shows that it was the genetic modification that was the source of the ill effects.

Pusztai indicated in his interview that his research seemed to show that a diet including GM potatoes was damaging to the rats' health. In the course of the interview he stated that, if given the choice, he would not eat the GM potatoes [16] and suggested that to put GM foods on the market would be to "use our fellow citizens as guinea pigs" [17]. At this time, GM foods were widely used in the USA, and the European Union was considering whether to allow their use in the EU. For an industry which wished to promote GM foods in Europe, Pusztai's remarks were highly provocative. The ensuing controversy drew in the Royal Society (RS), the Nuffield Council on Bioethics, The British Medical Association, and the UK government.

The debate raged over many media sources, both popular and scientific. So polarized was (and is) the debate that it is difficult to find an impartial forum. One forum which fairly reveals the various interests and values underlying the debate is the UK medical journal, The Lancet. To illustrate the divergent interests and values in the debate the following analysis will draw almost entirely on the development of the debate in The Lancet between May and November 1999.

\section{The beginning of the debate 22 may 1999}

The debate in The Lancet began with a News item [18] announcing three reports released on 18 May 1999. The first was that of the British Medical Association (BMA) which expressed the view that GM crops "should not be grown in the UK until proven safe." The second was a report from the UK Select Committee on Science and Technology which held that there was already a:

...de facto moratorium on commercial planting in place (but that it had) seen no evidence to suggest that the risks associated with growing GM crops or eating GM crops are high enough to justify calls that have been made for a moratorium.

The third was the Royal Society's "Review of data on possible toxicity of GM potatoes" [19]. The five page review starts with the assertion that:

...on the basis of the information available to us, it appears that the reported work from the Rowett (Pusztai's work) is flawed in many aspects of design, execution and analysis and that no conclusions should be drawn from it.

It is immediately clear that the government's Select Committee and the Royal Society (RS) do not see Pusztai's results as cause for concern, apart from the fact that the RS reiterates an earlier suggestion that anybody concerned with regulation of GM foods should give particular "consideration to whether long-term animal feeding studies are necessary to provide greater information on allergenicity or toxicity". The Lancet's News item then gives the flavour of the government's attitude to GM crops by reporting that:

The Minister for the Cabinet Office, Jack Cunningham called the BMA's position "outrageous and totally unacceptable" and "even more extreme than the environmental lobbyists".

The BMA, on the other hand, held that there simply was not enough known about the health risks posed by consumption of GM foods, and that production should not be allowed until the level of scientific 
uncertainty is sufficient to make the risk acceptable, since, as BMA head of research said, "some animal experiments have suggested that GM foods can be toxic". All three reports mentioned in this News item are responding to Pusztai's televised remarks, and they all give early indications of the positions of each of these participants in this debate.

\section{The lancet in defence of science 29 may 1999}

Fuel was added to the debate the following week (29 May 1999) when an editorial [20] in The Lancet, entitled "Health Risks of Genetically Modified Foods" maintained that the reason for promoting GM crops was profit, not altruism or a solution to food needs in developing nations. The editorial argued that this commercial interest explains why so little attention is paid to the potential health hazards of GM foods. The editorial finds it "astounding" that the US Food and Drug Administration (FDA) continues its policy of considering the health risks of GM crops to be the same as any other new crop plant "despite good reasons to believe that specific risks may exist". These good reasons are to be found in the results of Pusztai's research. The editorial accuses the Royal Society of "breathtaking impertinence" in passing judgment on Pusztai's work without the full and final publication of that work. The editorial concludes that "Governments should never have allowed these products into the food chain without insisting on rigorous testing for effects on health." Needless to say, this frontal attack on the critics of Pusztai drew considerable fire from them, and a series of five letters appeared five weeks later in the Correspondence section [21] of The Lancet.

\section{Response to The lancet's editorial 3 july 1999}

In the first letter, Peter Lachmann begins with the emotional remark that "it is a sad day for UK medicine when first the BMA and then The Lancet, in your May 29 editorial, align themselves with the tabloid press in opposition to the Royal Society and the Nuffield Council on Bioethics." He concludes with the same emotion, stating that "The attempt of single interest groups, supported by the tabloid press and now by others who should know better, to declare this whole technology as dangerous and immoral is sad for the UK, but it is also absurd.... what this campaign of vilification does to the science base and the prosperity of the UK may be serious." This last claim reveals one of the underlying values that motivates the advocates of GM technology - the value that The Lancet noted first in its editorial of 29 May - namely profit (or, perhaps more benignly, national wealth creation).

This is a motivating value that is not often explicitly mentioned, but is clearly a driving force for the GM industry, and for the UK government which sees the primary mission of science as enhancing industrial competitiveness and creation of national wealth. This policy was established in 1993 by the Conservative government's white paper, Realizing our Potential, and, despite various changes of government, has not been changed since then [22]. In the second letter Alan Malcom states clearly: "Of course the motive behind the commercial production of anything is added shareholder value". There is, however, another value which is more often explicitly mentioned, and that is the possible benefit to humanity of GM technology. Lachmann notes that GM may enable the development of plants that grow in saline-polluted soil, and possibly plants that need less water. He then suggests that the process of photosynthesis could even be improved so as to increase significantly the productivity of our crops. In general, these two values, profit and social benefit, underlie much of what is said in support of GM.
These values underlie arguments intended to show the safety of GM foods. There are two forms of argument that frequently appear in defence of the safety of GM. An example of the first is Lachmann's argument that: "There is no experimental evidence nor any plausible mechanism by which the process of genetic modification can make plants hazardous to human beings." Malcom offers the same argument in his letter: "Nobody...has been able to identify any potential health risk associated with consumption of lecithin, or soya oil, or soya stach obtained from a GM crop". Both Lachmann and Malcom make this claim in spite of Pusztai's work. The logic here is that if someone offers evidence for a claim (such as GM food is hazardous) and you do not want to accept the claim, you simply deny the evidence. This is a recurrent form of argument used by GM advocates. We might call it the hazard denier's argument since it simply denies evidence of hazards.

Lachmann offers an instance of the second popular form of argument when he says: " 300 million Americans and a billion Chinese eat genetically modified food with neither ill effects nor hysteria." The difficulty with this claim is that we do not know if there are ill effects. For centuries people smoked tobacco and did not recognize any ill effects of this. The only way that the ill effects of smoking were established was through epidemiological studies of smokers and nonsmokers. Here of course it was easy enough to know if someone was a smoker. In the case of GM foods, without labelling GM foods there is no such easy way to identify the consumers, and hence little chance of discovering the ill effects of GM as we did discover for tobacco.

The third letter responding to The Lancet editorial is from Carl Feldbaum (now retired) president of the Biotechnology Industry Organization (BIO), "the world's largest trade association representing biotechnology companies" [23], he adopts the tactic of changing the subject. He argues that the 29 May editorial misleads readers by saying biotechnology companies and government officals "have paid little evident attention to the potential hazards to health of genetically modified foods". The editorial ignores thousands of scientific studies, environmental risk assessments, and the field trials undertaken worldwide before the commercial introduction of transgenic crops.

Feldbaum goes on to discuss at length the environmental assessments conducted by the US Department of Agriculture. But, of course, these assessments are irrelevant to the health hazards of GM foods. When he does (eventually) get to the health hazards of GM foods, he correctly reports that the US Food and Drug Administration (FDA) has concluded that "because recombinant DNA techniques are used to introduce only one or a few genes into a crop, agricultural scientists avoid a major difficulty of conventional cross hybridisation, which is the multiple introduction of undesirable genes." The difficulty with this argument is that it supposes a one-one correlation between genes and traits. In fact it is well known that in the development of an organism various genes are involved in various ways in the production of phenotypic traits. This process, whereby one gene influences two or more seemingly unrelated phenotypic traits, is called pleiotropy [24].

An argument from authority appears in the fourth letter. $\mathrm{H}$. Schellekens maintains that the "editorial fails to make a continuing argument against the opinion of the US Food and Drug Administration that genetic modification does not constitute a risk in itelf." If the FDA can be trusted, this is a reasonable argument. But there is reason to believe that the FDA cannot be trusted in this matter. This issue is raised in the fifth and final letter. In this letter Eric Brunner and Erik Millstone point out the difficulties that arise when official regulatory authorities accept manufacturer's product analysis 
Page 5 of 8

without the control effected by peer review. They point to the example of rBST, a hormone which raises milk yield in dairy cows. They report that they found shortcomings in the manufacturer's unpublished analysis of rBST, but that they could not publish their findings because the manufacturer would not allow them to use the data in the unpublished analysis. The FDA approval was based on this unpublished analysis, accepted without the control of peer review. The suggestion is that, at least in this case, the FDA gave approval to a faulty product. In consequence, Brunner and Millstone "support the recent recommendation contained in the first report of the Commons Select Committee on Science and Technology for further openness in the regulatory process in the UK and elsewhere for new foods.... At this point it is worth mentioning that a recent, thorough, and well documented, study of the FDA process of approval of GM foods reveals that this approval has also been given without the openness and control of the peer review process [25].

\section{Publication of Ewen and Pusztai's paper 16 october 1999}

The next (and perhaps most) significant event in this debate was publication of the 16 October issue of The Lancet [26,27]. The "Commentary" section contained two commentaries on the GM debate - "Genetically modified foods: "absurd" concern or welcome dialogue?" by Richard Horton (editor of The Lancet); and "Adequacy of methods for testing the safety of genetically modified foods" by Kuiper Noteborn, and Peijnenburg. But most significantly, in the "Research letters" section it published a letter from Stanley Ewen and Arpad Pusztai reporting the effects of GM potatoes on the gastrointestinal tract of rats.

The title of Horton's commentary ..."absurd" concern or welcome dialogue?, is a reference to Peter Lachmann's assertion that public concern over the safety of GM technology was absurd. Horton then goes on to point out that Richard Sykes, (then) chairman of Glaxo Wellcome PLC also attacked public concern over GM technology quoting a remark from Sykes' presidential address to the British Association for the Advancement of Science:

It is now very possible that the outcomes of the present anti-GM food campaign will be detrimental to this country. It will lead to a failure to develop new UK companies based upon the technology developed here, loss of technical expertise as funding by major international companies is withdrawn, and disadvantage for British agriculture [26].

As chairman of Glaxo Wellcome PLC (soon to merge with SmithKline Beecham) Sykes was well placed to see the commercial promise of GM technology. Clearly he did not want public concern over the health hazards of the technology to interfere with the profits that the technology had to offer. This is perhaps the strongest indication published in The Lancet of the economic value that many find in GM technology.

Horton's motive for publishing Ewen and Pusztai's Letter was not to try and vindicate Pusztai's claims expressed 14 months earlier on Granada Television's programme World in Action. Horton was instead acting to alleviate public concern by publishing contentious scientific work so that it could be properly scrutinized by the scientific community. One of his motives in publishing the paper was that, as expressed by Robert May, the UK's chief scientific adviser, “...if the paper is not published, it will be claimed there is a conspiracy to suppress information" [28]. A further motive was the fact that several "respected scientists and scientific institutions," including the Royal
Society, recommended "more careful governmental scrutiny of research into GM food." It is worth noting that the RS also recommended further research into the impact of GM crops on the ecosystem, and the unpredictable genetic effects of the process of GM (which may include pleiotropy as mentioned earlier).

It is these attitudes which Horton saw as the cautious and responsible response to the new GM technology. He regards the comments by Lachmann and Sykes as "disappointing because they reflect a failure to understand the new, and apparently unwelcome, dialogue of accountability that needs to be forged between scientists and the public [28]." Moreover, with the publication of Ewen and Pusztai's paper, it becomes possible for the scientific community to engage in the technical (scientific) dialogue that Horton hoped will result in a resolution of this debate. Horton concludes that "Only by welcoming that debate will the standard of public conversation about science be raised. Berating critics rather than engaging them...will only intensify public scepticism about science and scientists [28]." This was a prescient remark that provided a warning, but unfortunately the warning was not heeded.

The Commentary by Kuiper, Noteborn, and Peijnenburg did just what their title suggested, it engaged in a scientific critique of the "Adequacy of methods for testing the safety of genetically modified foods" used by Ewen and Pusztai. Of course Ewan and Pusztai may not agree with their conclusion (as indeed they did not), but this is a scientific discussion, not the emotional berating of critics that The Lancet wants to eliminate. Toward the end of his commentary, Kuiper et al. pick up a recurrent theme. They say that: "Particular attention must be given to the detection and characterisation of unintended effects of genetic modification." And they further add that: "Inferences about such effects can no longer be based solely on chemical analysis of single macronutrients and micronutrients and known crop specific antinutrients or toxins [29]." In other words, novel toxins may result from the genetic modification. But, again, this is an empirical question, to be addressed using the methods of science. Unfortunately not all who responded to the publication of Ewen and Pusztais paper were able to maintain this standard of scientific discussion, as we shall see below.

\section{Response to the publication of Ewen and Pusztai's paper 13 november 1999}

The last instalment in this discussion taking place in The Lancet appears in the "Correspondence" section of the November 13th, 1999 issue of the journal [29]. It consists of eleven letters responding to the issue of 16th October, which had contained the editor's Commentary and the Letters by Ewen and Pusztai and by Fenton et al. The first three correspondents commented on Ewen and Pusztai's Letter of 16 October and were followed by a reply from Ewen and Pusztai; the fifth and sixth commented on the Letter from Fenton et al. with their reply; and the eighth, ninth and tenth commented on the 16th October Commentary by Richard Horton, editor of The Lancet, and were followed by his reply.

The first two correspondences addressed technical issues in the methods used, and observations made, by Ewen and Pusztai. This is exactly the scientific discussion that Horton was looking for in his publication of their paper. The second letter concluded by saying "We hope these comments will help to ensure that if these studies are repeated (as they should be), robust, rapid, and reliable methods... are used [29]." The third correspondence, from Peter Lachmann, was a 
Page 6 of 8

rather abrupt list of five reasons he found Ewen and Pusztai's letter "unacceptable", but, nonetheless, his comments addressed the methods and observations of the science. The reply by Ewen and Pusztai was clear and measured, addressing the concerns raised by the three preceding comments. They also noted that traits that have nothing to do with the transgene apart from its insertion have been found in other GM lines. For example, "The Monsanto analyses of glyphosateresistant soya showed that the GM-line contained about $28 \%$ more Kunitz trypsin inhibitor, a known antinutrient and allergen [30]." As a result they agree with Kuiper et al. in maintaining that "particular attention must be given to the detection and characterisation of unintended effects of genetic modification".

The second set of comments, directed at the paper by Fenton et al are, in keeping with the level of conversation encouraged by the editor of The Lancet, also concerned with method and observation. It is worth noting that the second of these comments makes the point that in "...the contentious work of Ewen and Pusztai... some other component of the construct used to transfect the GNA gene may be responsible for unexplained (and potentially harmful) consequences [30]." Fenton et al. respond in kind, discussing the scientific aspects of their Letter, and acknowledge that "GM potatoes are likely to contain other changes as a consequence of tissue culture (an intrinsic part of the GM process) [31]."

The level of conversation changes abruptly in the final set of three comments [32]. Carl Feldbaum, representing the biotechnology industry, rather emotionally remarks that:

Horton's decision to publish the research of Stanley Ewen and Arpad Pusztai breaks unfortunate new ground for a scientific journal. Put simply, The Lancet has placed politics and tabloid sensationalism above its responsibility to report and assess new science. Most peerreviewed journals are respected, and read, for the integrity of the research they publish and their dependability in weeding out irresponsible work.

\section{He later continues:}

This pandering to popular debate rather than promoting responsible scientific inquiry may appeal to some, but I believe that the editor's poor judgment will strengthen the resolve of other scientific journals to adhere to the publication standards The Lancet saw fit to abandon.

Roger Fisken writes in an equally emotional way, starting with the remark that:

It seems to be that we as scientists have not been nearly aggressive enough in attacking the scaremongering and sheer nonsense put out by the lay media on a variety of medical and scientific topics.

\section{And ending with the remark:}

Let us be proud of the scientific method and of scientific rigour. We must try to stop the slide into alarmism and negativity to innovation. In the Middle Ages superstition led to the burning of witches; if we are not careful it could soon be scientists who are being burned. By comparison, Aaron Klug's comments are relatively measured. Klug argues that, given the one-sided debate "raging [in the media] on the back of [Pusztai's] unvalidated experimental data" as reported in the television interview, the Royal society can hardly be accused of breathtaking impertinence for "examining such evidence as it could secure".

Horton's reply to this correspondence was measured and cogent. In response to those who addressed the science, he had little to say, only that "A debate about the science, rather than unsupported claims about that science, has now begun-a useful step forward." However his reply to Feldbaum was more pointed:

Ewen and Pusztai's research letter was published on grounds of scientific merit, as well as public interest. Four out of six invited reviewers recommended publication after revision on scientific grounds, one argued the public interest case, and one voted against publication. In the face of such clear support, the "irresponsible" action that Carl Feldbaum alludes to would have been to suppress publication. [my emphasis.]

In response to Klug, Horton replies that it was, at best, unfair and ill-judged for the RS to "review and then publish criticism of these researchers' findings without publishing either their original data or their response". In response to Fisken's call for scientists to be more aggressive, Horton notes that:

The Guardian newspaper has already reported one example of aggression, relating to The Lancet's decision to publish Ewen and Pusztai's work. That instance does not speak well of scientists' (in this case, a very senior scientist's) tolerance for open and reasoned debate.

\section{A History of Attacks on GM Dissent}

Prior to the Pusztai incident, scientific discussion of the safety of GM foods was open and reasoned - there seemed to be none of the virulence and emotion of the current discussion. But since the Pusztai incident, the tenor of the discussion has changed drastically. The Guardian report shows the beginnings of heavy handed criticism and treatment of those who dissent from the view that GM foods are safe.

\section{The Guardian report}

The Guardian report [32] began with the startling fact that two days before Richard Horton published Ewen and Pusztai's paper in The Lancet, Peter Lachmann had phoned him and aggressively told him that it would be immoral to publish the paper. It further reports that Lachmann told him that publishing the paper would "have implications for his personal position" as editor of The Lancet. But the deeper issue that this report brings to light is the fact that, according to "a source", the Royal Society was running a "rebuttal unit". The report states that the rebuttal unit was managed by Rebecca Bowden who had only joined the RS in 1998, coming from "the government biotechnology unit at the department of the environment, which controls the release of genetically modified organisms". The report further states that:

The rebuttal unit is said by the source to operate a database of likeminded Royal Society fellows who are updated by email on a daily basis about GM issues. The aim of the unit, according to the source, is to mould scientific and public opinion with a pro-biotech line. Dr Bowden confirmed that her main role is to coordinate biotech policy for the society, reporting to the president, Sir Aaron Klug. However, she and Sir Aaron denied it was a spin-doctoring operation.

The role of the UK government in this appeared in a leaked government memo which "outlined how its office of science and technology was compiling a list of eminent scientists who were on message to rebut criticism and underwrite the government's unequivocal pro-biotech line [32]." 
Page 7 of 8

\section{Judy Carman, Manuela Malatesta and Gilles-Eric Seralini}

The replacement of open and reasoned discussion of the safety of GM foods with personal attacks was an unwelcome turn in the nature of scientific discussion. However it still continues, and it is still unwelcome. There are numerous instances of this kind of response to those who dissent from the view that GM foods are safe. Three will serve to illustrate it. The first two were reported by Claire Robinson in the April 2015 issue of the New Internationalist Magazine [33].

In 2004, the Australian scientist Judy Carman published a chapter in a book which addressed critical perspectives on GM [34]. In the chapter she explored the potentially harmful effects of GM foods on human health. Subsequently she was given government funding for a GM feeding study on pigs. After that, Robinson reports,

...she suffered six personal attacks by pro-GMO scientists over a 10 year period. They attacked her through her university, alleging she was lying, bringing the university into disrepute, or defaming them.... Following the attacks, Carman says she was forced out of two successive university posts. Carman stated that Any scientist in my shoes relying on a university income to eat or pay a mortgage would feel forced to stop investigating GMOs.'

And With regard to Manuela Malatesta, Robinson reports that:

The Italian researcher found that Monsanto's GM soy disturbed the functioning of the liver, pancreas and testes of mice. After she published her papers, she says she was forced out of her job at the university where she had worked for 10 years, and could not obtain funding to follow up her research.

She commented: 'Research on GMOs is now taboo. You can't find money for it...People don't want to find answers to troubling questions. It's the result of widespread fear of Monsanto and GMOs in general'.

The most notorious case of bad behavior on the part of those who would defend the safety of GM against its critics was the treatment meted out to Gilles-Eric Seralini for the publication of his rat feeding studies in the journal Food and Chemical Toxicology. The Hastings Center, an independent, nonpartisan, and nonprofit American bioethics research institute founded in 1969, reported [35] that (quoting at length):

A sustained and vitriolic attack on Seralini's paper began within hours of publication. Thirteen letters to the editor were published in the journal, accusing the authors of a multitude of errors including using the wrong strain of rats, using the wrong number of rats, and animal cruelty for allowing tumors to grow to a large size. Fraud was implied. The authors wrote a comprehensive, reasoned response, and that should have been that

Instead, a year after publication, the journal announced that it was retracting the study. The quality of Seralini's work aside, the process by which his paper was retracted reeks of industry pressure. The progression of science is not the least bit linear, but the process has to proceed unencumbered by censorship of unpopular or commercially disadvantageous results. ... It would have been perfectly appropriate for the journal to have written an editorial expressing its concerns. Instead, it seems the editors may have succumbed to industry pressure to do the wrong thing.

The incidents reported in the Guardian and the attacks on Carman, Malatesta and Séralini show how the open and reasoned debate characteristic of science was replaced by vitriolic and personal attacks on those who would dissent from the view that GM is safe. This is a sad loss, since GM has the potential to offer much of benefit to humanity. But the tactics of its defenders puts it in such a bad light that the future of the science of GM is in jeopardy.

\section{The Human Benefits of GM}

A recurring theme in the response to GM critics, and one which contributes significantly to the emotion behind these responses, with its consequent breaking down of the decorum and open reasoned debate characteristic of science, is the idea that those who find problems with GM food crops are depriving humanity of the benefits which may result from this versatile technology. The technology does offer hope for improving crop production. We hear of increased yield, ability to grow in salty water, production of fruits and vegetables resistant to pests and spoilage. Further in the future we imagine grains which grow perennially, so all that is needed is annual harvesting and no more planting; and even improvements to the process of photosynthesis so that our crops can more efficiently use the sun's energy in food production.

At present, these are still visionary ideals, or, at best, in the early stages of development. One of the most celebrated GM improvements in crop production, much further along in the development, is Golden Rice [36]. This is a form of rice engineered by Ingo Potrykus and Peter Beyer, to produce a precursor to vitamin A. Their motivation was, like that of many academics, purely altruistic-they envisioned rice that would provide a social benefit. As a staple in the diet of many poor people in developing countries, it would provide a steady source of vitamin A thus alleviating the blindness and death that can result from vitamin A deficiency. Unfortunately, by the time Potrykus and Beyer began to develop Golden Rice, the biotechnology industry had become a powerful force in seed production and held control of much of the technology needed to produce Golden Rice. Potrykus and Beyer did a deal with the Swiss agrichemical company Zeneca (now Syngenta) to provide the technology they needed, in return for limited rights to the seed (the rice would be freely licensed to farmers whose annual turnover was less than $\$ 10000$, but would be commercially licensed to large-scale industrial farmers). The benefits to small scale farmers, their families and customers, are clear, and since small farmers produce most of the food in the developing world, the social benefit is also clear.

Currently, Golden Rice is still undergoing development and testing. It has not yet been made commercially available either to small scale farmers or to large scale producers. Pro-GM activists blame this on anti-GM activist resistance to the products of GM technology. But in fact the process of development and testing is more time consuming that was initially envisioned.

However, with Golden Rice the principle has been established - it is possible to introduce radical GM improvements into crop production which are beneficial to humanity. There are many scientists in the academic world working on such socially beneficial improvements; and they are, by and large, making the technologies that they develop freely available to other scientists and those who would put the technology into practice for the benefit of humanity. But these developments take time, and require adequate testing to ensure that changes brought about through the GM process do not have any adverse effect. Whether or not there are adverse effects cannot be know ahead of time-we cannot categorically say that all products of GM are safe or unsafe. In each case the final product must be tested. 


\section{Conclusion}

To understand the debate over the safety of GM food crops, it is necessary to look at the underlying values of the various participants and, above all, to recognize that many on both sides have a genuine interest in the good of humanity. However, the potential benefits of the technology should not blind us to the possible harm that may result from its use, its unintended consequences. Unfortunately, an industry that wishes to rush forward with this new technology has discovered that it can cloak its efforts in the guise of providing social benefits, of feeding the world. There are these benefits, but they must be developed and they must be tested. The safety of GM crops should be a matter for science to decide. It is an empirical question whether consumption of any particular GM food poses a hazard to human health. We cannot make a general claim about all GM food being safe or unsafe.

As those who study the process by which knowledge claims are established in science know well, those claims only count as knowledge when accepted by the community. And this means that they are potentially subject to spin - outside interests and values can influence what is accepted. With enough effort and resources, outside interests can establish the claim that all GM foods are safe. But that can only be done through the loss of open and reasonable debate - at the loss of science. The dialogue that took place in The Lancet between May and November of 1999 embodied a struggle between those who would have knowledge based on science and those who would have knowledge based on the interests of industry. Quite simply, in the case of Arpad Pusztai industry convinced the UK Government that GM will contribute to national wealth, and the Royal Society came to the aid of the Government. The dialogue that took place in The Lancet was not entirely conclusive, there are still voices calling for this debate to return to science. But the content and direction of the debate has been driven off the course of science by commercial values. As long as those values struggle against science, this debate will not be resolved.

\section{References}

1. McGrath MM, Strasser FF, (2012) Superweeds pose GM-resistant challenge for farmers. BBC News.

2. Koba M (2014) Superweeds Sprout Farmland Controversy Over GMOs. NBC News.

3. Neuman W, Pollack A (2010) Farmers Cope With Roundup-Resistant Weeds. The New York Times.

4. Registration of Enlist Duo (2015) EPA: United States Environmental Protection Agency.

5. Roundup Ready Xtend Crop System. Monsanto.

6. Statement by the AAAS Board of Directors On Labeling of Genetically Modified Foods (2012) American Association for the Advancement of Science, Pennsylvania, USA.

7. Statement: No scientific consensus on GMO safety (2013). European Network of Scientists for Social and Environmental Responsibility, Germany.

8. Hilbeck A, Binimelis R, Defarge N, Steinbrecher R, Szekacs A, et al. (2015) No scientific consensus on GMO safety. Environmental Sciences Europe 27: 4 .

9. Domingo JL, Bordonaba JG (2011) A literature review on the safety assessment of genetically modified plants. Environ Int 37: 734-742.

10. Snell C, Bernheim A, Berge JB, Kuntz M, Pascal G, et al. (2012) Assessment of the health impact of GM plant diets in long-term and multigenerational animal feeding trials: a literature review. Food Chem Toxicol 50: 1134-1148.
11. Nicolia A, Manzo A, Veronesi F, Rosellini D (2013) An overview of the last 10 years of genetically engineered crop safety research. Crit Rev Biotechnol 34: 77-88.

12. Sanchez MA (2015) Conflict of interests and evidence base for GM crops food/feed safety research. Nat Biotechnol 33: 135-137.

13. Seralini GE, Emilie Clair, Robin Mesnage, Steeve Gress, Nicolas Defarge et al. (2014) Republished study: long-term toxicity of a Roundup herbicide and a Roundup-tolerant genetically modified maize. Environmental Sciences Europe 26: 14.

14. Malatesta M, Boraldi F, Annovi G, Baldelli B, Battistelli S, et al. (2008) A long-term study on female mice fed on a genetically modified soybean: effects on liver ageing. Histochem Cell Biol 130: 967-977.

15. Roger Highfield (1999) Genetically modified crops: the ethical and social issues-The final report, published in May 1999.

16. Enserink M (1998) Institute Copes with Genetic Hot Potato. Science, New Series, 281: 1124-1125.

17. Arpad Pusztai (1999) Fears erupt over genetic food. BBC News, British Broadcasting Corporation, London.

18. Mitchell PP, Bradbury J (1999) British Medical Association enters GMcrop affray. The Lancet 353: 1769.

19. The Royal Society (1999) Review of data on possible toxicity of GM potatoes.

20. The Lancet (1999) Health risks of genetically modified foods. The Lancet 353: 1811.

21. Ewen SWB, Pusztai A (1999) Health risks of genetically modified foods. The Lancet 354: 69-71.

22. The Chancellor of the Duchy of Lancaster (1993) Realizing our Potential: A Strategy for Science, Engineering and Technology. London.

23. About Bio (2015) Biotechnology Industry Organization, USA.

24. Pleiotropy (2015) Wikipedia.

25. Druker S (2015) Altered Genes, Twisted Truths: How the Venture to Genetically Engineer Our Food Has Subverted Science, Corrupted Government, and Systematically Deceived the Public. Clear River Press, Salt Lake City, UT.

26. Horton R (1999) Genetically modified foods: "absurd" concern or welcome dialogue?. The Lancet 354: 1314-1315.

27. Ewen SW, Pusztai A, (1999) Effect of diets containing genetically modified potatoes expressing Galanthus nivalis lectin on rat small intestine. The Lancet 354: 1353-1355.

28. Kuiper HA, Noteborn HP, Peijnenburg AA (1999) Adequacy of methods for testing the safety of genetically modified foods. The Lancet 354: 1315-1316.

29. FitzGerald AJ, Goodlad RA, Wright NA (1999) GM food debate. The Lancet 354: 1725-1726.

30. Fenton B, Stanley K, Fenton S, Smitht CB (1999) GM food debate. The Lancet 354: 1728.

31. Fisken RA (1999) GM food debate. The Lancet 354: 1729.

32. Flynn L and Gillard MS (1992) Pro-GM food scientist threatened editor. The Guardian.

33. Robinson C (2015) Is Monsanto on the side of science? New Internationalist Magazine.

34. Carman J (2004) Is GM Food Safe to Eat? In: Recoding Nature Critical Perspectives on Genetic Engineering. UNSW Press, Sydney. p 82-93.

35. Berman FA, Sherman TG (2014) Rounding Up Scientific Journals. Bioethics Forum, The Hastings Center Report.

36. Jennings R (2013) Social and ethical issues raised by NGOs and how they can be understood. Successful Agricultural Innovation in Emerging Economies, Cambridge University Press, UK. pp. 386-399. 